\section{Studying the Market Potential for Specialty Cultivars of Sunflower Cut Flowers}

\author{
Kathryne Short ${ }^{1,4}$, Coleman L. Etheredge ${ }^{2,5}$, and \\ Tina M. Waliczek ${ }^{3,6,7}$
}

AdDitional INDEX wORDs. willingness to pay, WTP, floriculture, floral design, retail, wholesale, SCF, Helianthus annums

\begin{abstract}
Summary. In the United States, there is an increasing demand for field- or greenhouse-grown, specialty, locally grown cut flowers. However, certain cultivars of cut flowers are not readily available in the market. The purpose of this research was to produce a crop of novelty sunflowers (Helianthus annuns 'Firecracker') and study the marketability of the cut flowers to wholesale and retail florists and consumers. The plants were grown in greenhouses. Stems were harvested and shown to local floral wholesalers/retailers who were individually interviewed on their perceptions of the cut flower as a product. Farmers' market patrons were administered a quantitative survey to determine their perspectives on locally sourced products and willingness to pay (WTP) for the specialty cut flower (SCF). Results indicated half of the local florists interviewed responded positively to locally grown floral products in general, with all florists willing to pay at the least the same amount for the SCF as they are currently paying for their standard commercially grown, imported cut sunflowers. Farmers' market customers expressed a WTP of $\$ 1.34 /$ stem and/or $\$ 10.13 /$ bunch of 10 stems for the SCF with participants who expressed a higher concern for sourcing local products often more willing to pay a higher price for the SCF. Furthermore, among demographic comparisons, there were no differences in WTP based on age, income, and education. However, females were more likely to purchase the SCF when compared with males, and African-Americans were less likely to buy the SCF and willing to pay less for 10 stem bunches when compared with respondents of other ethnic backgrounds. Although many buyers responded positively to the product, results indicate women and those who prefer to buy local would be a good target demographic market for the product.
\end{abstract}

$\mathrm{H}$ istorically fresh cut flowers were used in rituals and ceremonies. For example, in the Middle East, prehistoric bones of a man were found ceremoniously laid out and covered with wild flowers over 50,000 years ago (Laufer, 1993). Today's typical consumer will purchase flowers for their own enjoyment or to give as a gift (Yue and Hall, 2010). Consumers purchase flowers based on a set of aesthetic attributes and the occasion for which the flowers are to be given [e.g., sympathy, apology, love, and appreciation (Yue and Hall, 2010)]. There are many factors tied to the purchasing

\footnotetext{
${ }^{1}$ Texas State University, San Marcos, TX 78666

${ }^{2}$ Department of Plant and Soil Sciences, Mississippi State University, Starkville, MS 39759

${ }^{3}$ Department of Agriculture, Texas State University, San Marcos, TX 78666

${ }^{4}$ Undergraduate student

${ }^{5}$ Assistant Professor

${ }^{6}$ Professor

${ }^{7}$ Corresponding author. E-mail: tc10@txstate.edu.

doi: 10.21273/HORTTECH03710-17
}

behavior of consumers such as income, purchasing occasion, relationship with recipient, and the availability of flowers (Yue and Hall, 2010). Understanding how these factors affect the spending habits of consumers allows the cut flower industry to more efficiently meet consumer demand (Yue and Hall, 2010).

Recent research has found factors such as color affects consumer preference and meaning associated for purchasing, as well as attaching different cut flower colors with different calendar and noncalendar occasions (Yue and Behe, 2010). Yue and Hall (2010) investigated how purchases of both traditional and specialty cut flowers have changed over time. The study found demographic characteristics played a role in the purchasing of flowers, with age, education, and income being major factors. Older participants ( 55 years and older) were less likely to buy SCFs, as well as people with lower education levels (Yue and Hall, 2010).

Local is often difficult to define and context driven (Holt and Watson, 2008). Much of the research regarding attitudes and perceptions of locally produced goods has been conducted concerning "food." "Food miles" is a term referring to the distance traveled from where an item was grown to the location of the consumer (Holt and Watson, 2008). Because of factors such as the concentration of the food supply base into fewer, larger suppliers and major changes in delivery patterns, and routing through delivery centers using heavy goods vehicles, there has been a major change in food production and its supply chain (Holt and Watson, 2008).

However, more interest has been garnered by consumers of other types of agricultural and horticultural products regarding local sourcing (Getter and Behe, 2013; Yue et al., 2011; Zaffou and Campbell, 2016). There is a lack of understanding among consumers of where agricultural and horticultural products originate and seasonality of products (Gairdner, 2006). One study found a majority of consumers would buy less imported products if they knew the distance products had traveled (Gairdner, 2006).

Although state regulations vary as to the definition of "local," $64 \%$ of consumers agreed that that products labeled "local" should be produced within 100 miles of where they are sold. One quarter of consumers felt that "local" included anything produced within the state (Rushing and Goldblatt, 2014). The U.S. Department of Agriculture (USDA) defines local as a product sold within 400 miles of its origin or within the state in which it was produced (Willcox, 2015). In Texas, the "Go Texan" campaign was developed by the Texas Department of Agriculture and is

\begin{tabular}{llll}
\hline $\begin{array}{l}\text { Units } \\
\text { To convert U.S. to SI, } \\
\text { multiply by }\end{array}$ & U.S. unit & SI unit & $\begin{array}{l}\text { To convert SI to U.S., } \\
\text { multiply by }\end{array}$ \\
\hline 3.7854 & gal & $\mathrm{L}$ & 0.2642 \\
2.54 & inch(es) & $\mathrm{cm}$ & 0.3937 \\
1.6093 & mile(s) & $\mathrm{km}$ & 0.6214
\end{tabular}


used to promote Texas products and producers. Guidelines as to the requirements regarding the use of the "Go Texan" campaign vary based on the product being sold (Willcox, 2015).

The sunflower is a plant native to North America domesticated by Native Americans. Evidence suggests the plant was cultivated by the Native Americans in Arizona and New Mexico as far back as $3000 \mathrm{BCE}$ and was used as a source of food, dye, and medicine (National Sunflower Association, 2015). It was in Russia that the sunflower became commercialized because sunflower oil could be used during Lent while most other oil foods were forbidden (National Sunflower Association, 2015). The specialty cut cultivar of sunflower, Firecracker, is described as a dwarf (16-36 inches stem length), bicolored (red and gold) sunflower, which produces multiple flower heads and is appropriate for pot cultivation (Johnny's Selected Seeds, Fairfield, ME).

Because of the wide range of flowers grown in the cut flower industry, a broad range of climatic conditions are needed for the growth of SCFs. This need provides growers in many regions an opportunity to take advantage of the potential SCF market, as well as to diversify their operations and improve profit margins (Kelly, 1991; Starman et al., 1995). According to a 2009 census of horticulture specialties, production of cut flowers in the United States is worth over $\$ 400$ million annually (Bogash et al., 2012). The vast majority of cut flowers are currently imported from the Netherlands, $\mathrm{Co}^{-}$ lumbia, Kenya, and Israel (Bogash et al., 2012). Most flowers grown locally are those that do not ship well or have shorter vase lives and are grown on a smaller scale (Bogash et al., 2012). An increase in demand for a wide cultivar of fresh cut flowers has kept the market growing (Bogash et al., 2012). The production of SCFs has the potential to fit well in a small scale farming operation as supplemental income (Bogash et al., 2012).

One research study investigating the productivity and profitability of annual and perennial field-grown SCFs found species that began producing shortly after planting and continued to produce many flowering stems per plant throughout the growing season resulted in the greatest profit potential (Starman et al., 1995). There are many cultivars of fast growing sunflower, some blooming as early as day 50 as well as many that will produce multiple stems (Cutler, 1997). Currently, the average cost of a standard sunflower is $\$ 7.50$ for five stems wholesale (U.S. Department of Agriculture, 2017). The suggested wholesale price for specialty cultivar of sunflowers is $\$ 6.00$ for three stems (J. Gonzales, personal communication; Scoggins, 2014). If the standard markup of three times the wholesale price is applied to the wholesale price (BloomNation, 2012), the retail price for a single stem of the specialty cultivar would be $\$ 6.00$ in comparison with $\$ 4.50$ for a standard sunflower.

The purpose of this study was to test the consumer willingness to pay rate of a locally grown SCF sunflower for the wholesale and retail cut flower industry.

\section{Materials and methods}

Cut Flower. The SCF used in this study was the sunflower, 'Firecracker'. Seeds were obtained from Johnny's Selected Seeds. Seeds were potted one seed per l-gal pot in general peat and perlite potting mix (Sunshine Mix \#1; Sun Gro Horticulture, Agawam, MA) for a total of 265 seeds potted. After $55 \mathrm{~d}$, flower stems began to be harvested. Flowers were harvested by hand during the $49 \mathrm{~d}$ of survey collection. Flower face size ranged from 4 to 6 inches. Vase life for all flowers harvested ranged from 16 to $18 \mathrm{~d}$.

Sample. Two sample groups were selected for this study including wholesale/retail florists who were interviewed and farmers' market patrons who were surveyed. Sample populations were chosen based on their willingness to participate and/or their experience in the floral wholesale/ retail industry. Participants were given incentives of packets of wildflower seed and/or the SCF stems in exchange for participation in the survey. Because the samples were those who volunteered instead of being randomly sampled, the results are not necessarily generalizable beyond this study.
Targeting farmers' market patrons and florists allowed researchers to include individuals in the study who were predisposed to participating in niche markets. This type of relationship marketing has been used to predict consumer behavior and potential markets in past studies (Shani and Chalasani, 1992). Farmer's markets are also known to be a popular direct marketing outlet for cut flowers (Connolly and McCracken, 2016).

WHOLESALE AND RETAIL FLORIST SAMPLE AND INTERVIEW SESSION. Qualitative interview data were collected from nine local retail and one wholesale florist in San Antonio, TX, and San Marcos, TX, who would potentially consider purchasing the sunflower to offer for sale for use in floral designs. When interview appointments were established, it was made clear the researcher would be interviewing the owner or individual at the establishment who made choices relating to ordering flowers for the business. Interviews lasted from 15 to $30 \mathrm{~min}$. Phone calls and in person visits were used to recruit participants. The first 10 florists who responded positively after initial contact were those included in the study. Ten was considered adequate as indicated from Morse's (2000) perspective that 6-10 participants were necessary for ideas to emerge from a target audience of those facing new market changes and/or profiting from market innovations [otherwise known as "lead users" (Lüthje and Herstatt, 2004)].

FLORIST SAMPLE AND INTERVIEW SEssion. A panel of experts made up of horticulture, agricultural business, marketing, and focus group researchers reviewed the questionnaire before administration and questions were based on those from previous reliable and valid studies (Glover et al., 2014). Florists were surveyed during mid to late spring season. The florists were given a sample of the SCF to analyze while they answered the questionnaire. The qualitative instrument consisted of nine open-ended questions asked in an interview style format and gathered thought and sensory perceptions of the flower (Huang and Yeh, 2009), the niche floral qualifiers of "local" and "organic" (Kelley et al., 2006; Nie and Zepeda, 2011), and how the 
florists chose wholesale or grower suppliers (Kallas et al., 2011). Niche product terms were defined in basic terms for the florists. "Local" was defined as a crop or merchandise originating within the region in which it is now being sold. "Organic" was defined as being produced without the use of pesticides, synthetic fertilizers, or other chemical inputs and being free of growth hormones and genetically modified organisms. In addition to attitudes and purchasing habits, one question asked florists how much they would be willing to pay for a stem of the SCF. Another asked their WTP for a bunch of 10 stems. All interviews were given by one researcher and all responses were recorded by hand; any questions from participants were answered by the researcher to the best of her ability.

FARMERS' MARKET QUANTITATIVE SURVEY. Quantitative survey data were collected during the mid to late spring season from patrons of local farmers' markets who agreed to take the survey based on that they would potentially consider purchasing the SCF. The survey instrument consisted of 32 questions within four different sections. The Cronbach's alpha reliability score for the instrument was 0.663 , which is considered an adequate level for this type of research (Gall et al., 2006). Reliability of an instrument is the measurement of internal consistency and the assuredness that the instrument would yield similar results in different situations or experiments. The first section of the survey included 11 five-point Likert-type (Likert, 1932) questions ranging from "strongly agree" to "strongly disagree" pertaining to participants' perceptions of environmental concerns. Examples of questions included, "I think of myself as an environmentally responsible shopper," and "when I buy a product, I take ecological considerations into account" (Glover et al., 2014).

The second section consisted of eight questions in which participants were asked to observe the SCF sunflower and were asked questions related to price premiums. Answer options consisted of multiple choice lists and free response open-ended areas. Examples of questions included, "would you buy this cultivar of sunflower," "how much would you pay per stem for this specialty cut flower," and "given a situation where a classictype bunch of sunflowers were offered at $\$ 9.99 /$ bunch (10 stems), how much would you be willing to pay for a bunch (10 stems) of this specialty cultivar of sunflowers?" (Glover et al., 2014; Krystallis and Chryssochoidis, 2005). A seed packet with a photograph of a sunflower with yellow petals and a dark brown to black center was available for reference in case questions arose as to what was considered a "classic-type bunch of sunflowers," although most respondents were familiar with the flower as both a cut material and a regional roadside wildflower.

The third section consisted of eight questions pertaining to each participant's personal purchasing habits relating toward local and organic purchasing. Participants were asked to choose from multiple choice answers listing various frequency of purchasing habit options. Examples of questions asked included, "I bought a product that was locally grown in Texas in the last year," "I typically buy food at a box store (Wal-Mart, H-E-B)," and "I typically buy food at a local farmers' market" (Glover et al., 2014; Krystallis and Chryssochoidis, 2005).

The final section consisted of five demographic questions asking participants to provide their age, education level, annual household income, gender, and ethnicity. These were based on a reliable instrument used in a previous similar study (Glover et al., 2014).

QUANTitative DATA ANALYsis. Data from the farmers' markets were analyzed using descriptive and frequency statistics. Pearson's productmoment correlation tests were used to determine if there were correlations between variables. Demographic comparisons were also made between groups using analysis of variance (ANOVA) tests.

QUALITATIVE DATA ANALYSIS. Interview data were organized by themes, which included positive, negative, and neutral comments. Because participants could give a mixture of answers, responses could register in more than one theme. The results were summarized using frequency statistics. Qualitative questions requiring factual responses, rather than attitudes, were tabulated.

\section{Results}

Of the 170 participants, 10 were local florists providing in-depth qualitative interviews and 160 were farmers' market customer responses providing quantitative data.

REgIONAL FLORIST ATTITUDES TOWARD LOCALLY GROWN FLOWERS. When asked about their opinion concerning the sunflower being grown locally, half of the florists (five) surveyed responded positively. Examples of comments included, "another selling point to customers," "more important than organic," and "in support to keep it local if possible." Three of the florists (30\%) responded with neutral answers. Examples of neutral comments included, "nonissue," "little importance," and "no answer." Finally, two florists (20\%) responded negatively. Examples of negative comments included, "it does not help my bottom line" and "can't depend on local timing."

REgIONAL FLORIST SELF-REPORTED WTP. All florists (10) responding were willing to pay similarly to the cost that they were already paying for traditional sunflowers with the mean reported WTP rate being $\$ 0.79 /$ stem $(\mathrm{SD}=0.22)$. Wholesale cost of cut sunflowers is often between $\$ 0.65$ and $\$ 1.00$ per stem (Sam's West Inc., 2017).

REgional FLORIST ATtitudes TOWARD ORGANIC. When asked their attitudes concerning the term "organic" as it relates to cut flowers, half of the florists (5) responded positively. Examples of comments included, "it would be great for my older employees who may be sensitive and handling the flowers day in and day out could pose a problem to their health" and, "as a designer, I care a great deal about organic." Two florists $(20 \%)$ responded with neutral comments. Examples of neutral comments included, "I do organic at home but not at the shop." Three florists $(30 \%)$ responded negatively. Examples of comments included, "it does not impress me," "price is more important than gimmick," and "Why do I care? My customers won't be eating them."

In this study, a few of the florists seemed aware of the potential risks involved with current production standards and the potential benefits of using of floral and foliage materials 
grown using organic methods. Most flowers are imported from other countries (Bogash et al., 2012), and need to meet plant health regulations which leads to heavy pesticide applications before exportation (Toumi et al., 2016). Because cut flower and foliage products are not grown for consumption, these crops are not required to meet maximum residue limits for pesticides and can be treated with pesticides up to or during harvest (Toumi et al., 2016). Many of the pesticides used can be absorbed through the skin and are fat soluble. Health problems related to exposure to the heavy pesticide use on cut floral products have been reported (Abell et al., 2000). However, recent marketing research found that consumers are responding positively to organic production and labeling regarding ornamental plants (Rihn et al., 2016).

FARMERS' MARKET CUSTOMERS SELF-REPORTED WTP. Participants were first asked if they would buy the SCF sunflower. Results found that $134(84.8 \%)$ responded they would be willing to purchase the SCF. Participants who responded they would be willing to purchase the SCF cultivar were then asked how much they would be willing to pay for a single stem of the flower. Overall, $40(29 \%)$ indicated a WTP of $\$ 1.00 /$ stem, $20(14.5 \%)$ indicated a WTP of $\$ 0.50 /$ stem, and $16(11.6 \%)$ indicated a WTP of $\$ 1.50 /$ stem. The mean WTP was $\$ 1.34 /$ stem $(\mathrm{SD}=$ $\$ 1.52$ ).

Participants were then asked how much more or less they would pay beyond a price of $\$ 9.99$ per 10 -stem bunch. Overall, 35 (22.2\%) indicated a WTP of $\$ 0.50$ more per bunch for 10 stems, 28 (17.7\%) indicated a WTP of $\$ 1.00$ more per bunch for 10 stems, and 18 (11.4\%) indicated a WTP of $\$ 2.00$ more per bunch for 10 stems. The mean was $\$ 10.13$ for a bunch of 10 stems $(S D=\$ 3.80)$. Therefore, overall results of this study showed the specialty cut sunflower garners a similar price to that of the currently marketed classic sunflower.

FARMERS' MARKET CUSTOMERS ATTITUDES TOWARD LOCALLY GROWN FLOWERS. Participants were asked to respond to 11 questions pertaining to attitudes toward local purchasing. An attitude toward local purchasing score was summed for each participant with 11 indicating low concern toward sourcing locally grown products and 55 indicating high concern toward sourcing locally grown products. Three categories were established a priori and included "low" (11-25), "medium" (26-40), and "high" (41-55). Similar groupings were established and used in interpreting results in previous studies (McFarland et al., 2008, 2010).

The mean score of those responding was 31.28 indicating, on average, participants had a medium level of concern toward local purchasing. Correlation tests were run to determine if there was a relationship between farmers' market customers' attitudes toward local purchasing and their willingness to purchase the SCF, and a statistically significant relationship was found $[P=0.005$ (Table 1 )] with customers who had more positive feelings toward local purchasing willing to pay more for the SCF. Descriptive statistics showed that consumers who had a medium level of concern toward locally sourced products were willing to pay $\$ 1.47$ per individual stem and $\$ 10.62 /$ bunch, whereas those with a high level of concern were willing to pay $\$ 1.71 /$ stem and $\$ 10.71$ per 10 -stem bunch. This is as much as $\$ 0.37$ more per stem and $\$ 0.57$ more per bunch for the SCF compared with the overall mean. Past research found farmers' market patrons to have a medium level of concern toward locally sourced foods (Glover et al., 2014) and consumers willing to pay more for products indicating locally produced labels (Hu et al., 2012).

FARMERS' MARKET CUSTOMERS ATTITUDES TOWARD THE ENVIRONMENT. Participants were asked to respond to questions pertaining to attitudes toward the environment. An attitude toward the environment score was summed for each participant with five indicating low concern for the environment and 30 indicating high concern for the environment. Three categories of scores were established before the initiation of the study and included: "low" (5-13), "medium" (14-22), and "high" (23-30) concern for the environment. Similar groupings were established and used in interpreting results in previous studies (McFarland et al., 2008, 2010).

The mean score of the study was 22.68 indicating, on average, participants had a borderline medium to high level of concern toward the environment. Correlation tests were run to determine if there was a relationship between farmers' market customers' attitudes toward the environment and their WTP for the SCF. No statistically significant correlation was found on these comparisons $[P=$ 0.065 (Table 1)]. Past research indicated that environmental attitudes can influence consumer behaviors with those concerned with the environment buying more "green" products (Mainieri et al., 1997).

FARMERS' MARKET CUSTOMERS ATtitudes TOWARD ORganic. Participants were asked to respond to one

Table 1. Pearson's product-moment correlation results of the relationship between consumers' willingness to pay (WTP) for the specialty sunflower, WTP above or below $\$ 9.99$ per bunch, environmental attitude score, attitudes toward organic production score, and attitudes toward local production score in the study of the market potential for specialty cultivars of sunflower cut flowers.

\begin{tabular}{|c|c|c|c|c|}
\hline Dependent variable & & $\begin{array}{c}\text { Environmental } \\
\text { attitudes }\end{array}$ & $\begin{array}{l}\text { Attitudes toward } \\
\text { organic production }\end{array}$ & $\begin{array}{l}\text { Attitudes toward } \\
\text { local production }\end{array}$ \\
\hline \multirow[t]{3}{*}{ Would you buy this flower? } & Pearson correlation & 0.147 & 0.074 & 0.224 \\
\hline & $P$ & 0.065 & 0.355 & $0.005^{*}$ \\
\hline & $N$ & 158 & 158 & 158 \\
\hline \multirow{2}{*}{$\begin{array}{l}\text { How much more or less willing to pay for } \\
\text { a bunch of } 10 \text { stems offered at } \$ 9.99 \text { ? }\end{array}$} & Pearson correlation & 0.048 & 0.005 & 0.248 \\
\hline & $P$ & 0.546 & 0.948 & $0.002 *$ \\
\hline
\end{tabular}

* Statistically significant at $P \leq 0.05$. 
question pertaining to attitudes toward organic production. An attitude toward organic production score was summed for each participant with one indicating low concern toward organic production and 5 indicating high concern toward organic production. The mean score of the study was 4.35 indicating, on average, participants had a positive view of organic production. Correlation tests were run to determine if there was a relationship between farmers' market customers' attitudes toward organically grown products and their WTP for the SCF as single stems or in bunches. No statistically significant correlation was found in these comparisons $[P=0.355$ (Table 1$)]$. Although past studies have linked consumer behavior and positive attitudes toward organic products (Bruschi et al., 2015), no correlation was found in consumers' affinity toward the SCF based on their perceptions of organic production.

D E M O G R A P H I C D A T A COMPARISONS. An ANOVA test was conducted to determine if there was a difference in the way demographic groups answered questions pertaining to their WTP for the SCF, how much they were willing to pay per stem for the SCF, and how much more or less they were willing to pay for a bunch of 10 stems of the SCF. There were no statistically significant differences in WTP per stem or per bunch in comparisons of different farmer's market shoppers based on income, education, and age. This showed that respondents with these different characteristics were similar in the price point of $\$ 1.34 /$ stem and $\$ 10.13 /$ bunch.

A statistically significant difference was found between the way male and female participants responded to

Table 2. Analysis of variance results of demographic comparisons by gender and ethnicity of farmers' market customers' responses to questions regarding consumers' willingness to buy a specialty cut flower in the study of the market potential for specialty cultivars of sunflower cut flowers.

\begin{tabular}{|c|c|c|c|c|c|}
\hline Dependent variable & Yes $[$ no. $(\%)]$ & No $[$ no. $(\%)]$ & df & $F$ & $P$ \\
\hline \multicolumn{6}{|l|}{ Gender } \\
\hline \multicolumn{6}{|c|}{ Would you buy this flower? } \\
\hline Females & $106(90.6)$ & $7(6.0)$ & & & \\
\hline \multicolumn{6}{|l|}{ Ethnicity } \\
\hline \multicolumn{6}{|c|}{ Would you buy this flower? } \\
\hline Asian & $3(100)$ & $0(0)$ & & & \\
\hline African American & $2(50)$ & $2(50)$ & & & \\
\hline Other & $11(91.7)$ & $3(11.1)$ & & & \\
\hline
\end{tabular}

*Statistically significant at $P \leq 0.05$.

Table 3. Analysis of variance results of demographic comparisons by gender and ethnicity of farmers' market customers' responses to questions regarding how much consumers are willing to spend per stem, and how much they are willing to pay (WTP) per 10-stem bunch in the study of the market potential for specialty cultivars of sunflower cut flowers.

\begin{tabular}{|c|c|c|c|c|c|}
\hline Dependent variable & Mean WTP & SD & df & $F$ & $P$ \\
\hline \multicolumn{6}{|l|}{ How much are you WTP per stem? } \\
\hline Females & 1.301 & 1.312 & & & \\
\hline \multicolumn{6}{|l|}{$\begin{array}{l}\text { How much more or less willing to pay for a bunch of } \\
10 \text { stems offered at } \$ 9.99 \text { ? }\end{array}$} \\
\hline \multicolumn{6}{|l|}{ Ethnicity } \\
\hline How much are you WTP per stem? & & & 4 & 0.241 & 0.951 \\
\hline Caucasian & 1.403 & & & & \\
\hline Hispanic & 1.327 & & & & \\
\hline Asian & 1.330 & & & & \\
\hline Caucasian & 9.897 & & & & \\
\hline Hispanic & 11.444 & & & & \\
\hline Asian & 12.000 & & & & \\
\hline African American & 6.2000 & & & & \\
\hline Other & 10.333 & & & & \\
\hline
\end{tabular}

* Statistically significant at $P \leq 0.05$. 
the question, "Would you buy this SCF?" $[P=0.002$ (Table 2)]. Frequency statistics revealed females $(90.60 \%)$ were more likely to respond "yes" to this question when compared with males $(64.90 \%)$ (Table 2 ). Yeh and Huang (2009) reported differences in the needs of male and female consumers of floral products. Therefore, they recommended marketing products differently based on gender.

Furthermore, statistically significant differences were found in comparisons by ethnicity on the question, "Would you buy this SCF?" $[P=$ 0.041 (Table 3)] and, "A bunch of 10 stems of the SCF is offered at $\$ 9.99$. How much would you be willing to pay?" $[P=0.046$ (Table $3)$ ]. Post hoc comparisons [least significant difference (LSD)] found that African Americans differed from all other groups. Frequency statistics showed African Americans were the least likely to purchase the SCF (Table 3 ) and that African Americans were willing to pay the least per bunch at $\$ 6.20$ (Table 3). However, the sample size for African Americans was very small in the overall sample and may not be generalizable to larger samples.

\section{Conclusion}

Findings showed that all local florists were willing to pay at least the same amount for the specialty sunflower cultivar that they are currently paying for commercially grown imported standard sunflowers. Half of the local florists were in favor of sourcing flowers from local farms and expressed an interest in sourcing organic flowers.

A majority of farmers' market patrons $(84.8 \%)$ indicated a willingness to purchase the SCF sunflower. On average participants indicated a WTP of $\$ 1.34 /$ stem and/or $\$ 10.13$ per bunch of 10 stems for the SCF with participants who expressed a higher concern for sourcing local products more often willing to pay a high cost for the SCF. These results do not support the recommended price of $\$ 6.00$ for three stems of specialty sunflowers (Scoggins, 2014), but is similar to the average price of $\$ 7.50$ for five stems wholesale (U.S. Department of Agriculture, 2017). However, this research only looked at stated prices consumers claimed they were willing to pay for the SCF and findings on the amount consumers would actually pay could vary had they been forced to really purchase the SCF. Other factors that could potentially shift the price level at which a consumer would be willing to pay for flowers include region, time of year, market and community characteristics, and numerous other local conditions (Connolly and McCracken, 2016).

Past research found that those over 55 years old and of lower income and education being less likely to buy SCFs (Yue and Hall, 2010). Although this study did not find differences in those categories, differences were found in gender comparisons. Although no differences were found in the amount females were willing to spend on the flower when compared with men, descriptive statistics showed that individuals in this study with a greater concern for locally sourced products were willing to pay as much as $\$ 0.37$ more per stem and $\$ 0.57$ more per bunch for the SCF.

In this study, most florists and farmers' market patrons responded positively to the SCF and would pay similarly to prices of currently available standard sunflowers. Although many SCFs demand a higher price, this lower price point may be adequate because the flower should require no additional inputs beyond current production requirements for the standard sunflower (Putnam et al., 2017). Therefore, this product could be produced with similar profit margins. Because the plant is native to North America and able to be produced in both field and greenhouse conditions, it could offer a unique niche market and create the opportunity to diversify amongst local growers across the country which was identified as a need in past research (Kelly, 1991; Putnam et al., 2017, Starman et al., 1995). In addition, previous research has shown that particular market groups including light users of flowers are drawn to new cultivars such as this one (Baourakis et al., 2000).

These findings indicate there is potential for florists in the central Texas region to source and sell SCF cultivars that have been grown locally at a higher price to particular customers. These findings also display an opportunity for local farmers to potentially fill a niche market that is lacking in the cut flower industry by offering SCF cultivars that have been grown locally to the regional florists and farmers' market patrons.

\section{Literature cited}

Abell, A., E. Ernst, and J.P. Bonde. 2000. Semen quality and sexual hormones in workers. Scand. J. Work Environ. Health 26(6):492-500.

Baourakis, G., D. Gerasopoulos, N. Kalofolias, N. Kalogeras, and A. Zoumis. 2000. Marketing research: The case of floral products. Acta Hort. 541:227-232.

BloomNation. 2012. Basic pricing. $10 \mathrm{Jan}$. 2015. <http://www.bloomnation.com/ flowercloud/2012/11/basic-pricing/>.

Bogash, S.M., T.G. Ford, L.F. Kime, and J.K. Harper. 2012. Cut flower production. 14 June 2017. <http://extension. psu.edu/business/ag-alternatives / horticulture/specialty-crops/cut-flowerproduction $>$.

Bruschi, V., K. Shershneva, I. Dolgopolova, M. Canavari, and R. Teuber. 2015. Consumers perceptions of organic food in emerging markets: Evidence from Saint Petersburg, Russia. Agribusiness Intl. J. 31(3):414-432.

Connolly, J.R. and V.A. McCracken. 2016. Cut flower prices at farmers markets: A bouquet pricing study. 5 June 2017. $<$ https://pubs.wsu.edu/ItemDetail.aspx? ProductID $=15848 \&$ Series Code $=\&$ CategoryID $=158 \&$ Keyword $>$.

Cutler, K.D. 1997. The complete vegetable and herb gardener: A guide to growing your garden organically. MacMillan, New York, NY.

Gairdner, J. 2006. Local food is miles better: The farmers weekly food miles campaign. Reed Business Info., Sutton, UK.

Gall, M.D., J.P. Gall, and W.R. Borg. 2006. Educational research: An introduction. 8th ed. Allyn and Bacon, White Plains, NY.

Getter, K. and B. Behe. 2013. Attitudes and awareness of a "buy local" holiday marketing campaign. HortTechnology 23:877-885.

Glover, B.J., T.M. Waliczek, and J.M. Gandonou. 2014. Self-reported willingness to pay for Texas persimmon fruit as a food source. HortTechnology 24:1-10.

Holt, D. and A. Watson. 2008. Exploring the dilemma of local sourcing versus international development - The case of the flower industry. Bus. Strategy Environ. 17(5): 318-329. 
Hu, W., M.T. Batte, T. Woods, and S. Ernst. 2012. Consumer preferences for local production and other value-added label claims for a processed food product. Agr. Econ. 39(3):489-510.

Huang, L. and T. Yeh. 2009. Floral consumption values for consumer groups with different purchase choices for flowers. HortTechnology 19:563-571.

Kallas, Z., F. Lambarraa, and J. Gil. 2011. A stated preference analysis comparing the analytical hierarchy process versus choice experiments. Food Qual. Prefer. 22(2): 181-192.

Kelley, K.M., J. Conklin, J. Sellmer, and R. Bates. 2006. Invasive plant species: Results of a consumer awareness, knowledge, and expectations survey conducted in Pennsylvania. J. Environ. Hort. 24(1): 53-58.

Kelly, J.W. 1991. Field production of cut flowers. HortScience 26:1136-1138.

Krystallis, A. and G. Chryssochoidis. 2005. Consumers' willingness to pay for organic food: Factors that affect it and variation per organic product type. Brit. Food J. 107(5):320-343.

Laufer, G.A. 1993. Tussie-mussies: The Victorian art of expressing yourself in the language of flowers. Workman Publ., New York, NY.

Likert, R. 1932. A technique for the measurement of attitudes. Arch. Psychol. 22(140):55.

Lüthje, C. and C. Herstatt. 2004. The lead user method: An outline of empirical findings and issues for future research. R\&D Mgt. 34(5):553-568.

Mainieri, T., E. Barnett, T. Valdero, J. Unipan, and S. Oskamp. 1997. Green buying: The influence of environmental concern on consumer behavior. J. Soc. Psychol. 137(2):189-204.

McFarland, A., T.M. Waliczek, and J.M. Zajicek. 2008. The relationship between student use of campus green spaces and perceptions of quality of life. HortTechnology 18:232-238.

McFarland, A., T.M. Waliczek, and J.M. Zajicek. 2010. Graduate student use of campus green spaces and the impact on their perceptions of quality of life. HortTechnology 20:186-192.

Morse, J.M. 2000. Determining sample size. Qual. Health Res. 10(1):3-5

National Sunflower Association. 2015. All about sunflowers. 10 Jan. 2015. <http:// www.sunflowernsa.com/all-about/ history $/>$.

Nie, C. and L. Zepeda. 2011. Lifestyle segmentation of US food shoppers to examine organic and local food consumption. Appetite 57:28-37.

Putnam, D.H., E.S. Oplinger, D.R. Hicks, B.R. Durgan, D.M. Noetzel, R.A. Meronuck, J.D. Doll, and E.E. Schulte. 2017. Sunflower. Alternative field crops manual. 4 Mar. 2017. <https://www. hort.purdue.edu/newcrop/afcm / sunflower.html>.

Rihn, A., H. Khachatryan, B. Campbell, C. Hall, and B. Behe. 2016. Consumer preferences for organic production methods and origin promotions on ornamental plants: Evidence from eyetracking experiments. Agr. Econ. 47:599608.

Rushing, J. and M. Goldblatt. 2014. Ripe for grocers: The local food movement. 8 June 2017. <https://www.atkearney. com/documents/10192/4503223/ Ripe+for+Grocers+-+The+Local+Food + Movement.pdf/cf378al7-8e42-4082a038-0df1806ddca6>.

Sam's West Inc. 2017. Sam's club bulk flowers, sunflowers. 24 Jan. 2017 <http://www.samsclub.com/sams/ mini-sunflowers-yellow-100-stems/ prod4750263.ip? xid=plp 1253 -jewe: product:1:1>

Scoggins, H. 2014. Marketing specialty cut flowers. 10 Jan. 2015. <http://www extension.org/pages $/ 70577 /$ marketingspecialty-cut-flowers\#.VVT6QflVhBc>.

Shani, D. and S. Chalasani. 1992. Exploiting niches using relationship marketing. J. Consumer Mktg. 9(3):33-42.

Starman, T., T.A. Cerny, and A.J. MacKenzie. 1995. Productivity and profitability of some field-grown specialty cut flowers. HortScience 30:1217-1220.

Toumi, K., C. Vleminckx, J. van Loco, and B. Schiffers. 2016. Pesticide residues on three cut flower species and potential exposure of florists in Belgium. Intl. J. Environ. Res. Public Health 13:943. <https://www.ncbi.nlm.nih.gov/pmc/ articles/PMC5086682/\#B2 1-ijerph-1300943>.

U.S. Department of Agriculture. 2017. Report results. 9 May 2017. <https://www. marketnews.usda.gov/mnp/fv-report-topfilters? loc $\mathrm{Name}=\& \operatorname{commAbr}=S U N F \&$ c o $\mathrm{m} \mathrm{m} \mathrm{N}$ a $\mathrm{m} \mathrm{e}=\mathrm{S}$ U N F L O W E R \& class Name $=$ ORNAMENTALS \& row Display $M$ ax $=25 \&$ start Index $=1 \&$ navClass $=$ ORNAMENTALS\&navType $=$ byComm\&rep Type $=$ termPriceDaily $\&$ type $=$ termPrice $>$.

Willcox, K. 2015. How do you define what makes a product local? It's complicated. 7 June 2017. <https://vinepair. com/wine-blog/how-do-you-definelocal $/>$.

Yeh, T.F. and L.C. Huang. 2009. An analysis of floral consumption values and their difference for genders and geographic regions. HortTechnology 19:101-107.

Yue, C. and B.K. Behe. 2010. Consumers' preference for cut-flower color on calendar and non-calendar occasions. HortScience 45:78-82.

Yue, C., J. Dennis, B. Behe, C. Hall, B. Campbell, and R. Lopez. 2011. Investigating consumer preference for organic, local, or sustainable plants. HortScience 46:610-615

Yue, C. and C. Hall. 2010. Traditional or specialty cut flowers? Estimating U.S. consumers' choice of cut flowers at noncalendar occasions. HortScience 45:382386.

Zaffou, M. and B. Campbell. 2016. Consumer preference and willingness to pay for azaleas: Effect of state labeling and various types of retail outlets. HortScience 51:1026-1030. 